\title{
O ESPAÇO, O TEMPO E A (DES)CONSTRUÇÃO DE UMA REALIDADE INTEGRADA
}

\author{
SPACE, TIME, AND THE (UN)DEVELOPMENT OF AN \\ INTEGRATED REALITY
}

\author{
EL ESPACIO, EL TIEMPO Y LA (DES)CONSTRUCCIÓN DE \\ UNA REALIDAD INTEGRADA
}

\author{
Marcelo de Mello - Universidade Estadual de Goiás - Goiânia - Goiás - Brasil \\ mellogeo28@yahoo.com.br
}

\section{Resumo}

A Geografia tem subsidiado o diálogo do homem com 0 mundo desde a antiguidade clássica. Investigações centradas nas relações travadas entre a unidade e a diversidade, reveladas pelo mundo, estão entre os temas clássicos deste saber transformado em ciência moderna. Ciência moderna consolidada no bojo de revoluções burguesas que garantiram o triunfo da razão humana sobre os mitos e as crenças que, por séculos, condenaram o homem a uma condição de servidão. Para tanto, houve uma série de especializações científicas para atender as demandas de uma burguesia carente dos conhecimentos imprescindíveis à dominação da natureza, bem com a transformação desta em mercadorias. Neste movimento de adequação da realidade percebida às demandas produtivas, o tempo e o espaço foram decantados e classificados de acordo com virtudes e defeitos a eles atribuídos previamente. 0 espaço foi classificado como imobilizador das dinâmicas sociais. Esta categoria de análise foi vinculada aos estudos privilegiadores de perspectivas lineares, enquanto 0 tempo assumiu a condição de mediador conceitual nos estudos em que a contradição se fazia presente. Para romper com esta perspectiva equivocada, 0 espaço está sendo reinserido nas teorias sociais críticas, com o intuito de superar as reduções desta separação arbitrária.

Palavras-chave: espaço, tempo, homem, conhecimento.

\begin{abstract}
Geography has assisted the dialogue between man and the world since classical antiquity. Investigations focusing on relationships that take place between unity and diversity, as revealed by the world, are among the classical subjects of this knowledge transformed into modern science. Modern science was accomplished by the ability of the bourgeois revolutions in ensuring the triumph of human reason against myths and beliefs that, for centuries, condemned man to a condition of servitude. To this end, there was a series of scientific improvements to meet the demands of a bourgeoisie in need of knowledge, essential to the domination of nature as well as to its transformation into commodities. In this process of adaptation of reality to the demands of production, time and environment were decanted and classified according to virtues and faults attributed to them previously. The environment was classified as an immobilizer of social dynamics. This category of analysis has been linked to studies which are prone to linear perspectives, as time took on a mediating conceptual role in which the contradiction was present. To break this mistaken perspective, the environment is being reinserted into critical social theories in order to overcome the reductionism of such arbitrary separation. Key words: space, time, men, knowledge.
\end{abstract}

\section{Resumen}

La Geografía viene subsidiando el dialogo del hombre con el mundo desde la antigüedad clásica. Investigaciones centradas en las relaciones trabadas entre la unidad y la diversidad, reveladas por el mundo, están entre los temas clásicos de este saber transformado en ciencia moderna. Ciencia moderna consolidada en el centro de 
las revoluciones burguesas que garantizaron el triunfo de la razón humana sobre los mitos y las creencias que, por siglos, condenaron el hombre a una condición de esclavitud. Para tanto, hubo una serie de especializaciones científicas para atender a las demandas de la una burguesía carente de los conocimientos necesarios a la dominación de la naturaleza, bien con la transformación de esta en mercadurías, En este movimiento de adecuación de la realidad percibida a las demandas productivas, el tiempo y el espacio fueron decantados y clasificados de acuerdo con virtudes y defectos a ellos atribuidos previamente. El espacio fue clasificado como inmovilizador de las dinámicas sociales. Esta categoría de análisis fue vinculada a los estudios privilegiadores de perspectivas lineares, en cuanto el tiempo asumió la condición de mediador conceptual en los estudios en que la contradicción se hacia presente. Para romper con esta perspectiva equivocada, el espacio está siendo reinsertado en las teorías sociales críticas con la finalidad de superar las reducciones de esta separación arbitraria.

Palabras clave: espacio, tiempo, hombre, conocimiento.

Introdução

Podemos afirmar que a relação da Geografia com a produção do conhecimento tem sido marcada por uma história extremamente rica. Contudo, devemos ressaltar que esta assertiva não pode ficar restrita à ciência geográfica forjada sob o fogo criado pelas demandas burguesas delineadas, sobretudo, nos séculos XVIII e XIX. Isto porque um saber geográfico menos recortado e mais abrangente vem, desde os períodos clássicos, oferecendo uma gama infinita de possibilidades para os que se dedicam a decifrar ou a criar um ordenamento para as "coisas" presentes no mundo, no universo.

A relação do homem com a natureza e a procura incessante por referências balizadoras de sua relação com o mundo vêm, há séculos, compelindo o homem à realização de inúmeras investigações geográficas. E, no curso destes processos investigativos, foram formuladas distintas propostas para a decifração do mundo.

Certamente, os saberes geográficos ${ }^{1}$ têm auxiliado o homem no atendimento de uma necessidade fundamental que lhe é inerente: situá-lo no mundo. A indicação da existência de mais de um mundo e de mais de um homem pode ser compreendida quando consideramos as inúmeras referências utilizadas para definir a posição do homem perante o mundo. Se diferentes perspectivas concebem posicionamentos distintos ao homem em sua relação com o mundo teremos, forçosamente, diversos entendimentos sobre o homem e sobre o mundo.

Entre os elementos colocados em pauta, tendo em vista uma compreensão aprofundada desta intrincada relação, um pode ser destacado por ter ocupado - e ainda ocupar - uma posição privilegiada no cerne dos 
debates e descobertas que vieram a imprimir uma maior complexidade na realidade percebida e avaliada: trata-se do movimento. Isso porque a aceitação da existência do movimento, ou de movimentos, abriu caminho para a formulação de questionamentos sobre uma visão de mundo que determinava um caráter absoluto ao ordenamento das coisas no mundo, bem como a posição do homem diante destas coisas.

Assim, a constatação de que o movimento existe e não poupa nada nem ninguém tornou possível a negação do estado de imobilidade $^{2}$ fundamental, que limitava a percepção das relações travadas entre o homem, o tempo e o espaço situados no mundo, no universo. Estas relações se defrontaram com a imponderabilidade inerente à presença do movimento e passaram a revelar uma dimensão extremamente complexa, pois um dos atributos apresentados pelo movimento foi a não cessação definitiva, a não interrupção plena. Esse caráter permanente do movimento colocou o homem diante de um estado incontido de transformações e não de uma simples e definitiva alteração no posicionamento das coisas presentes no mundo.

\section{A realidade: entre a restrição e a possibilidade}

Apesar das descobertas que revelaram um mundo mais complexo do que o considerado pelas convenções medievais, as abordagens centradas em perspectivas imobilizadoras continuam, no mundo hodierno, tendo um peso expressivo nos mais diversos estudos dedicados ao entendimento da relação do homem com o mundo.

Esse fato chama ainda mais a atenção quando verificamos que a revolução científica, advinda da sistematização dos conhecimentos realizada por Newton, ocorreu no século XVIII. A partir de então, o movimento não pôde mais ser refutado e os corpos em estado de deslocamento comprovado passaram a desafiar qualquer tentativa de imobilização.

$\mathrm{E}$, se isso não bastasse, uma nova constatação incrementou ainda mais a dinâmica do mundo: se, em Newton, a forma absoluta de ver um mundo estático foi superada pela descoberta de um movimento também absoluto, dois séculos depois, a revolução continuou "seu curso", com a superação da ideia de movimento absoluto, apresentada pelo físico do século XVIII. Einstein ${ }^{3}$ demonstrou o caráter relativo do movimento que, 
por sua vez, conferiu uma gama infinita de possibilidades vinculadas à percepção do homem acerca do espaço e do tempo.

Todavia, na atualidade, em detrimento de todas essas descobertas científicas e dos novos veículos que ampliaram o acesso à informação, na maioria das vezes em que estas questões são abordadas é invocada a necessidade de um cuidado na forma empregada para apresentar fatos e/ ou eventos que expressem um vínculo com as dimensões espaçotemporais. Esse cuidado é justificado pela necessidade do combate a dois riscos. Primeiro, evitar que as "coisas" fiquem "embaralhadas" na cabeça do ouvinte desavisado, que, apesar de viver em um mundo caracterizado pela movimentação frenética, tem seus horizontes limitados pelos objetivos comuns de uma sociedade standartizada, programada. Segundo, para que a "ambígua" categoria espaço não venha, novamente, a servir como "ferramenta" para a fundação de um modelo opressor de mundo. Assim, é difundida a ideia de que o homem tem sua liberdade garantida por meio de um progresso vinculado à categoria tempo e que o espaço está associado a posicionamentos reacionários. ${ }^{4}$

Não estamos afirmando que as "coisas" tenham que ser envolvidas por complicações premeditadas com o simples propósito de criar confusões ou que a produção do conhecimento - de qualquer conhecimento - não necessite de reflexões que possibilitem a avaliação dos sentidos e da natureza de seus usos. Mas um fato levantado por Santos (2000, p. 17) deve ser destacado para que o cuidado não dê lugar a reduções que comprometam a compreensão da realidade percebida: "vivemos num mundo confuso e confusamente percebido".

Partindo desta premissa, o próximo tópico apresenta um debate em torno de considerações formuladas por um geógrafo que investiga as relações travadas entre o homem, o espaço, o tempo, a produção e o mundo.

Soja e a reafirmação do espaço na teoria social crítica

Vamos, a partir de agora, recorrer a Soja (1993) para abordar a longa e intrincada relação mantida entre o homem, o espaço, o tempo, a produção e o mundo e, assim, apresentar algumas razões que fizeram com que o espaço fosse visto com reservas por vários pensadores/formuladores de teorias, sistemas e ideias classificadas como revolucionárias. O motivo da 
escolha deste autor se encontra grafado no subtítulo de uma de suas obras: “à reafirmação do espaço na teoria social crítica”, bem como na possibilidade de, por meio dela, situar o espaço no interior das teorias críticas mais expressivas para o conhecimento produzido pela geografia.

Iniciaremos esta empreitada com um questionamento: o que levou à necessidade de uma "reafirmação do espaço na teoria social crítica"? Este subtítulo nos faz imaginar que, em um primeiro momento, o espaço ocupou um lugar central nas formulações teóricas que objetivaram um reordenamento na posição de segmentos sociais. Entendemos que este momento específico pode ser associado à Renascença, quando a pintura em perspectiva emerge como uma forma revolucionária de representação espacial. Posteriormente, com o ressurgimento e a consolidação das relações comerciais na Europa, houve a transposição da pintura em perspectiva da arte para a cartografia, com o intuito de possibilitar o deslocamento do homem no espaço.

No que diz respeito ao "mundo das ideias", as obras de Descartes, Maquiavel, Newton, Kant e tantos outros, deram ao espaço um tratamento próprio, nas quais aparecem destacadas diferentes possibilidades de percepção e de ação do homem, que pôde se posicionar diante de um mundo espacialmente referenciado.

Se concordarmos que este pode ser considerado um momento em que o espaço foi visto com certa deferência, como identificar e entender o processo que o levou a uma condição marginal no âmbito das teorias sociais críticas elaboradas ao longo do século XIX, bem como no decorrer de grande parte do século XX?

Sobre isso, Soja inicia sua obra discorrendo a respeito da obsessão do século XIX pela história, enfatizada pela compreensão de um mundo "primordialmente, através da dinâmica decorrente do posicionamento do ser e do devir sociais nos contextos interpretativos do tempo" (Soja, 1993, p. 17). O autor ressalta que sua "intenção não é apagar a hermenêutica histórica, mas abrir e recompor o território da imaginação histórica através de uma espacialização empírica”. Contudo, antes mesmo de anunciar sua intenção, ele afirma que "ainda não estamos suficientemente seguros desta espacialização incipiente da teoria crítica para fornecer uma exposição epistemológica abrangente e confiante"; foi a partir do surgimento de uma série de fatos e fenômenos, que vieram a formar o que Soja (p. 19) chamou de geografias pós-modernas, que o conhecimento produzido 
progrediu o bastante para mudar significativamente a paisagem material do mundo contemporâneo e o campo interpretativo da teoria crítica. É chegado o momento, portanto, ao menos de uma primeira rodada de avaliação receptiva desses dois contextos cambiantes da história e da geografia, da modernidade e da pós-modernidade - um concretamente impresso no tecido empírico da vida contemporânea (a geografia pós-moderna do mundo material), e o outro ziguezagueando pelas maneiras como damos sentido prático e político ao presente, ao passado e ao futuro potencial (a geografia pós-moderna da consciência social crítica).

Cabe, agora, esclarecer o que o autor classifica como Geografias Pós-modernas. Assumindo esta tarefa, vamos encontrar, sem muita dificuldade, os elementos por ele destacados para revelar a "instauração" de uma "passagem para a pós-modernidade". Trata-se de uma transição fortemente vinculada a acontecimentos - classificados como explosivos - ocorridos no final da década de 1970. Esses acontecimentos, segundo o autor, indicaram o fim do "longo surto de crescimento do pós-guerra na economia capitalista” (p. 78); fato que, por sua vez, exigiu uma reestruturação desse modo de produção.

Esse cenário nebuloso suscitou uma enorme gama de debates, nos quais novas possibilidades foram consideradas. Podemos dizer que, mais uma vez, o homem se defrontou com um "novo mundo". Entretanto, não era um mundo desconhecido, que exigia a classificação de coisas nunca antes vistas; e sim um "novo mundo" repleto de coisas conhecidas e classificadas que, graças à superação das condições que garantiam a reprodução do capitalismo, se viu obrigado a passar por um processo de ressignificação. Esta conjuntura possibilitou ao espaço adquirir outro peso nas considerações que mensuravam as realidades que eram descortinadas.

Alguns intelectuais passaram a afirmar que a análise das condições históricas não era mais suficiente para dar conta do novo mundo que se impunha. Não se travava mais de entender a realidade somente por meio das narrativas diacrônicas, fugindo de um espaço sincrônico que não significava nada além da possibilidade de confinar o tempo - ou a temporalidade. ${ }^{5}$ Era imprescindível a formulação de estratégias que dessem conta de um mundo marcado por um modo de produção que solicitava a criação simultânea de vários espaços e de vários tempos.

Algumas teorias sociais críticas, formuladas a partir de então, possibilitaram que o espaço fosse assumido como uma instância incontornável para aqueles que se interessassem em explicar ou compreender os 
processos produtores do mundo plural e de suas incontáveis diversidades. Para Soja (1993, p. 78), "uma outra cultura do espaço e do tempo parece estar-se formando nesse contexto contemporâneo e redefinindo a natureza e a experiência da vida cotidiana no mundo moderno - e, com elas, todo o tecido da vida social".

Sobre essa outra cultura do espaço e do tempo, o autor afirma que

está em sintonia com as mudanças na maneira com que pensamos e reagimos às particularidades - aos perigos e às possibilidades - do momento contemporâneo, através da ciência, da arte, da filosofia e dos programas de ação política. O pós-modernismo se superpõe ao pós-historicismo e ao pós-fordismo como discurso teórico e como conceito periodizante em que a geografia tem importância cada vez maior como ponto de vista do discernimento crítico. (p. 79)

A dimensão da relação entre o tempo e o espaço enfatizou a desigualdade que tem caracterizado o peso destas categorias no interior das ciências humanas nos séculos XIX e XX. Mas uma explicação anunciada não foi até agora apresentada de forma objetiva: trata-se das "causas" que fizeram com que o espaço fosse desprestigiado em sua relação com o tempo por um período tão longo. Na realidade, é válido dizer que a situação de marginalidade em que se encontra o espaço não foi definitivamente resolvida; por esse motivo, trataremos disso a seguir.

\section{O lugar do espaço e da Geografia nas ciências humanas}

A condição marginal em que se encontra o espaço pode ser entendida a partir das profundas relações estabelecidas entre a Geografia e os interesses do Estado. É possível afirmar que a proximidade entre esta ciência e o Estado antecede o caráter moderno adquirido por ambos. Isso fica explícito quando recordamos o momento em que o espaço foi visto como categoria fundamental na formatação de uma visão de mundo que permitiu a ascensão da burguesia no interior do próprio feudalismo. ${ }^{6} \mathrm{Ou}$ seja, se, a princípio, o espaço e o saber geográfico demonstraram uma vocação revolucionária por combater o poder que sustentava a ordem feudal, num momento posterior o conhecimento produzido pela Geografia serviu ao Estado burguês, que fez uso deste para promover a expansão e o domínio do modo de produção capitalista pelo mundo. 
Podemos apontar para esta direção quando avaliamos as dificuldades enfrentadas pelos que se empenharam no projeto de reafirmação do espaço na teoria social crítica. Algo contraditório no processo de construção dos argumentos que fomentam os preconceitos, que há muito perseguem a Geografia e o espaço, é que não ocorreu um conjunto de ações isoladas que deu corpo à ciência geográfica e outro conjunto que fez surgir as demais ciências humanas. Se a Geografia demorou mais tempo para ser sistematizada foi em razão da longevidade apresentada pelas narrativas dos geógrafos, que dificultaram o processo de inserção da objetividade e da universalidade no conhecimento por ela produzido (Gomes, 1996), como exigia a versão moderna de se produzir conhecimentos científicos.

Todas as áreas do conhecimento que passaram a responder aos ditames da ciência moderna atenderam, de alguma forma, às condições impostas pelo modo de vida mercantilista. Este penetrou em todas as esferas das relações sociais, espaciais, temporais e produtivas. São inúmeros os autores (Gomes, 1996; Santos, 2000; Horkheimer, 2003; Mello, 2009; Moreira, 2008) que vinculam a segmentação das áreas do conhecimento e o advento das ciências modernas fragmentadas à necessidade de dar respostas às demandas vertiginosas produzidas pelo capitalismo.

Percebemos, então, que um sistema produtivo pautado em uma reprodução ampliada do capital, obtida através da produção de mercadorias, afetou substancialmente as maneiras de viver e de se relacionar com o tempo, com o espaço e com a produção. Essa afetação tem um sentido de "continuidade”, ou seja, ela não é interrompida. Essa não interrupção é entendida quando consideramos que os obstáculos ao bom funcionamento desse sistema são decorrentes de sua própria reprodução.

Isso porque o funcionamento regular das estruturas produtivas conduz a contradições comprometedoras de uma ordem estabelecida. A realidade abstraída, idealizada e modelizada pelos agentes produtivos articulada e engendrada no espaço - não é reproduzida pela eternidade. Pelo contrário, as modelizações que inspiram os circuitos produtivos são, inevitavelmente, afrontadas por elementos presentes em uma realidade concreta e contraditória desconsiderada pelos formuladores de uma ordem linear.

Nesse contexto, a reprodução ampliada do capital obriga a um redimensionamento incessante da lógica produtiva, com a finalidade de superação dos limites produzidos por um sistema gerador de contradições 
sistematicamente negadas. Limites, estes, invariavelmente relacionados a questões que põem em relevo estas "duas" dimensões da realidade: o tempo e o espaço.

Assim, a tarefa de buscar soluções para os gargalos que comprometem a capacidade produtiva foi conferida à razão humana. Esta, por sua vez, é salvaguardada pela ciência moderna. Além dessa tarefa, coube à ciência moderna orientar a formulação das bases diretivas capazes de encaminhar bem ações do Estado moderno, que se constituiu na expressão máxima da possibilidade do exercício da liberdade e da emancipação humana. Tudo isso, com base em uma visão de mundo em que a fragmentação da realidade se configurou como a grande estratégia capaz de garantir a superação dos limites que, irremediavelmente, vão desafiar o homem. Desafio eterno, em que as ciências parceladas se tornaram portos seguros à medida que foram conquistando status de produtoras de um conhecimento progressivo.

O "rito de passagem" que guiou a transição dos diversos saberes, vistos como carentes de um ordenamento rigoroso, à condição de conhecimentos modernos, cientificamente embasados, foi a aceitação do posicionamento de cada ciência no interior do projeto que guiou a fragmentação do território da academia científica, de acordo com os interesses hegemônicos.

Essa configuração permitiu que as ciências modernas - fragmentadas - passassem a ser as responsáveis pelo estudo de objetos específicos numa perspectiva também específica: o espaço (re)produzido pelo homem, por exemplo, é conhecido como objeto de estudo da Geografia. Como essa visão fragmentada de mundo veio a formar diversas áreas do conhecimento que não necessitam do diálogo para serem reconhecidas, tornou-se possível responsabilizar um dos fragmentos incumbidos de produzir conhecimento por certos desvios e equívocos, enquanto outros permanecem atrelados a uma ação virtuosa, manifestada, por exemplo, pela personalidade revolucionária associada ao tempo e à história.

\section{Considerações finais}

Nesse ponto, entendemos que uma afirmação se torna necessária: a realidade percebida pelo homem não se assemelha a um quebra-cabeças. Esse tipo de visão é equivocada. Não podemos considerá-la como se tudo 
que viesse a compor o mundo pudesse ser dividido em blocos contínuos, de maneira que a ausência de algumas peças não comprometesse a visão geral do conjunto. Reduzir a importância de uma peça, isolá-la ou mesmo culpá-la por qualquer desvio, como se as relações não fossem dialéticas, é um engano.

A capacidade de eleger culpados acompanha o processo de produção de homens, espaços, tempos e mundos abstratos e fragmentados, produzidos pelo modelo exposto neste artigo. Isso porque, se a culpa não puder ser atribuída a um elemento que pode ser isolado e exilado, o sistema que rege a sociedade será visto como potencialmente falível. Um mundo que tem suas bases fincadas na ciência moderna e no Estado republicano não pode deixar que os sistemas racionalmente elaborados sejam percebidos como deficientes. Eles devem ser entendidos como "infalíveis", porque a sociedade aspira por um progresso universal que depende deles.

Nessa perspectiva, vale ressaltar que a fragmentação das ciências que conduziu ao entendimento moderno do mundo-repercutiu no homem. Se o mundo foi decantado por sistemas racionais que procuraram formas de potencializar a dominação exercida por um modelo produtivo, é certo que essa fragmentação penetrou e invadiu o homem, que, à semelhança do mundo, foi desintegrado. O homem, o espaço, o tempo, a produção e o conhecimento foram parcelados por uma lógica que não conhece outro sentido além da acumulação e da concentração de riquezas. Qualquer ação que vislumbre outro objetivo é classificada como improcedente. É comum o uso do termo "romântico" - pejorativamente - para qualificar atitudes em que um fim utilitarista não esteja no comando das ações empreendidas. Como registrado nas obras dos fundadores da Escola de Frankfurt - Horkheimer e Adorno -, a própria existência humana passou a ser justificada por meio de pensamentos utilitaristas que transformaram o homem - que tanto buscou a liberdade - em escravo de uma racionalidade instrumental por ele reproduzida.

Portanto, a mediação da relação do homem com o mundo foi emparedada por uma racionalidade em que os elementos privilegiados são os que interessam a uma vida e a uma produção instrumentalizadas. Esse ordenamento instituído serve a um modelo de produção e reprodução de riquezas que exige uma ininterrupta adequação por parte do homem. Ele deve ser capaz de dar respostas às demandas sempre renovadas por um sistema produtivo que, apesar de não reconhecer, tem como uma de suas 
marcas a produção de contradições. Nos discursos dos agentes responsáveis pelas interpretações dos estados de crise ${ }^{8}$ derivados das contradições, não assumidas pelo sistema, os cenários apresentados revelam os gargalos que devem ser superados para que não haja um comprometimento da ordem que garante a imprescindível reprodução ampliada do capital.

Esse movimento de superação de limites pela ordem econômica está sendo intensificado a cada dia. No mundo hodierno, esse processo tem influenciado, incisivamente, a configuração das relações em que o homem $^{9}$ aparece como mais um elemento. E uma das grandes virtudes a serem perseguidas pelo elemento/homem é demonstrada pela capacidade de adequação rápida a todas as mudanças que o afetam e envolvem o tempo, o espaço e a produção. A despeito de toda e qualquer mudança, o homem - qualificado pela razão instrumental ${ }^{10}$ que busca governar o sistema - deve ser capaz de situar-se e avaliar os cenários que são compostos e descompostos a sua frente.

Portanto, é oportuno retomarmos o alerta feito por Lacoste (1993) na década de 1970, quando afirma a necessidade de "saber pensar o espaço para saber nele se organizar, para saber ali combater”. É fundamental uma revisão que amplie possibilidades inerentes ao espaço como categoria de investigação da realidade. Dessa categoria arbitrária e artificialmente reduzida por interesses escamoteadores de realidades concretas, é indispensável a inserção definitiva do espaço nas teorias sociais críticas; só assim haverá uma transformação do mundo por meio de uma perspectiva reintegradora da realidade. Não podemos mais aceitar a fragmentação forçada do espaço-tempo. Até quando o espaço será circunscrito a um domínio inexistente do fechado, do imobilizado? Por quanto tempo, ainda, serão elaborados e aceitos sistemas pautados em representações conceituais exacerbadamente fragmentadas, produtoras de profundas incongruências com a realidade reproduzida de maneira conjugada e indissociável?

\section{Notas}

1. O conhecimento produzido tem como característica a sua validação por procedimentos formais elaborados pela ciência racionalista, que busca sistematizálo a partir de um conceito de verdade objetiva e universal. O saber, por sua vez, tem uma existência vinculada a processos em que a subjetividade e a particularidade possibilitam compreender a essência dos fatos, não se restringindo a seus aspectos externos. 
2. Fato que restringiu as ações do homem na Idade Média.

3. As ideias de Newton foram sistematizadas no texto Princípios Matemáticos da Filosofia Natural e as teses de Einstein estão localizadas na sua Teoria Geral de Relatividade.

4. O combate ao segundo risco pode ser entendido com base em uma postura que restrinja a dimensão espacial a ações estratégicas tendo em vista o controle e a dominação dos fortes sobre os fracos, e é comumente reportada a uma compreensão restrita e equivocada da obra de Ratzel, em que somente o tão propalado “determinismo ambiental” é enfatizado.

5. Massey (2008) apresenta o sentido conferido pelos antropólogos estruturalistas ao espaço. Ela destaca a maneira como o espaço foi posto como opositor do tempo, a partir de uma característica que lhe foi imposta e que o tornou uma ferramenta com a capacidade de imobilizar o movimento evidenciado pelo tempo. $\mathrm{O}$ que os antropólogos buscavam era uma ruptura com um modo narrativo de compreender a ideia de progresso presente na história. Nesse contexto, o espaço se tornou uma categoria privilegiada pela antropologia, por propiciar um entendimento alternativo através de análises de estruturas espaciais estáticas, classificadas como sincrônicas, por não contemplarem mudanças, superações; já que estas eram associadas à ideia de tempo.

6. Quando, no Renascimento, a pintura em perspectiva ofereceu os elementos que subsidiaram a cartografia moderna, fundamental, por exemplo, para as grandes navegações.

7. O romantismo foi um movimento filosófico, artístico e cultural que se destacou na Alemanha dos séculos XVIII e XIX. Ele se contrapôs ao racionalismo generalizador e universalizante advindo do Iluminismo.

8. Santos (2000) e Moreira (2008) defendem que as crises cíclicas produzidas pelo modo de produção hegemônico são produtos da própria estrutura sustentadora e reprodutora de um sistema contraditório.

9. Moreira (1987) aborda essa questão com base na elaboração do conceito de homem atópico.

10. O conceito de razão instrumental foi elaborado por Horkheimer (2003) e está relacionado ao uso da razão para dominar ao invés de emancipar.

\section{Referências}

GOMES, Paulo César da Costa. Geografia e modernidade. Rio de Janeiro: Bertrand Brasil, 1996.

HORKHEIMER, Max. Eclipse da razão. São Paulo: Centauro, 2003.

LACOSTE, Yves. A geografia - isso serve, em primeiro lugar, para fazer a guerra. São Paulo: Papirus, 1993.

MASSEY, Doreen. Pelo espaço: uma nova política da espacialidade. Rio de Janeiro: Bertrand Brasil, 2008. 
MELLO, Marcelo de. Brasília e Águas Lindas de Goiás: a loucura e a razão no processo de produção de um território. Tese (Doutorado) - IESA, Universidade Federal de Goiás, Goiânia, 2009.

MOREIRA, Ruy. O discurso do avesso: para a crítica a Geografia que se ensina. Rio de Janeiro: Dois Pontos, 1987.

MOREIRA, Ruy. O pensamento geográfico brasileiro: as matrizes clássicas originais. São Paulo: Contexto, 2008.

SANTOS, Milton. Por uma outra globalização. Rio de Janeiro/São Paulo: Record, 2000.

SOJA, Edward. Geografias pós-modernas: a reafirmação do espaço na teoria social crítica. Rio de Janeiro: Jorge Zahar, 1993.

Marcelo de Mello - Doutor em Geografia pela Universidade Federal de Goiás. Professor do Departamento de Geografia da Universidade Estadual de Goiás. 